\title{
Epistemic Orientation Short Scale: Development and Validity Evidence in a Sample of Psychotherapists ${ }^{1}$
}

\author{
Emanuel Missias Silva Palma², Sônia Maria Guedes Gondim², Carolina Villa Nova Aguiar ${ }^{3}$ \\ ${ }^{2}$ Universidade Federal da Bahia, Salvador-BA, Brazil \\ ${ }^{3}$ Escola Bahiana de Medicina e Saúde Pública, Salvador-BA, Brazil
}

\begin{abstract}
Epistemic orientation refers to the preferred mode of accessing and using knowledge and is a construct of growing interest in psychotherapy research. In this context, the main objective of this study was to develop and provide initial validity evidence for a brief measure of epistemic orientation in a sample of Brazilian psychotherapists. Participants were 674 Brazilian psychotherapists (78.5\% female), aged between 22 and 78 years. Exploratory and confirmatory factor analyses were conducted on different subsamples to establish the structure of the measure. Results revealed an instrument consisting of three factors (Rationalism, Intuitionism, and Empiricism) with good psychometric properties and fit indices $\left(X^{2}=1.92, \mathrm{GFI}=0.94, \mathrm{CFI}=0.95\right.$ and RMSEA $\left.=0.06\right)$. Factors exhibited good internal consistency and convergent and discriminant validity. Criterion validity was evaluated by examining the scale's ability to detect differences in the epistemic orientation dimensions as a function of therapist's theoretical approach. Overall, the scale proved to be a valid self-report measure for investigating personal epistemology.
\end{abstract}

Keywords: epistemology, psychotherapists, factor analysis, measurement

\section{Escala Breve de Orientação Epistêmica: Desenvolvimento e Evidência de Validade em uma Amostra de Psicoterapeutas}

\begin{abstract}
Resumo: A orientação epistêmica refere-se ao modo preferido de acesso e uso do conhecimento, sendo um construto de crescente interesse em pesquisa em psicoterapia. Nesse contexto, o objetivo principal do estudo foi desenvolver uma medida breve de orientação epistêmica e fornecer evidências iniciais de sua validade em uma amostra de psicoterapeutas brasileiros. Participaram 674 psicoterapeutas brasileiros (78,5\% mulheres), com idades entre 22 e 78 anos. Conduziram-se análises fatoriais exploratória e confirmatória em diferentes subamostras para estabelecer a estrutura da medida. Os resultados revelaram um instrumento composto por três fatores (Racionalismo, Intuicionismo e Empiricismo) com boas propriedades psicométricas e índices de ajustamento $\left(X^{2}=1,92, \mathrm{GFI}=0,94, \mathrm{CFI}=0,95\right.$ e RMSEA $\left.=0,06\right)$. Os fatores apresentaram boa consistência interna, validade convergente e discriminante. Avaliou-se a validade critério mediante a identificação de diferenças nas dimensões de orientação epistêmica em função da abordagem teórica do terapeuta. Em geral, a escala demonstrou ser um instrumento de autorrelato válido para investigação da epistemologia pessoal.
\end{abstract}

Palavras-chave: epistemologia, psicoterapeutas, análise fatorial, medidas

\section{Escala Breve de Orientación Epistémica: Desarrollo y Evidencia de Validez en una Muestra de Psicoterapeutas}

\begin{abstract}
Resumen: Orientación epistémica se refiere a la forma preferida de acceder y usar el conocimiento, siendo un constructo de creciente interés en investigación en psicoterapia. En ese contexto, el objetivo principal del estudio fue desarrollar y proporcionar evidencia inicial de validez para una corta medida de orientación epistémica en una muestra de psicoterapeutas brasileños. Participaron 674 psicoterapeutas brasileños (78.5\% mujeres), con edades entre 22 y 78. Análisis factoriales exploratorio y confirmatorio fueron realizados en diferentes submuestras para establecer su estructura. Resultados revelaron un instrumento con tres factores (Racionalismo, Intuicionismo y Empiricismo), buenas propiedades psicométricas e índices de ajuste $\left(X^{2}=1.92, \mathrm{GFI}=0.94, \mathrm{CFI}=0.95\right.$ y RMSEA $\left.=0.06\right)$. Los factores demostraron buena consistencia interna, validez convergente y discriminante. La validez de criterio se evaluó mediante su capacidad para detectar diferencias en las dimensiones de orientación epistémicas como función del enfoque teórico del terapeuta. En general, la escala demostró ser una medida de autoinforme válida para investigar la epistemología personal.
\end{abstract}

Palabras clave: epistemología, psicoterapeutas, análisis factorial, medidas

${ }^{1}$ Paper deriving from the doctoral dissertation by the first author, under the advice of the second author, defended in the Graduate Program in Psychology at the Universidade Federal da Bahia. Support: Coordination for the Improvement of Higher Education Personnel (CAPES).
Correspondence address: Emanuel Missias Silva Palma. Universidade Federal da Bahia. Faculdade de Filosofia e Ciências Humanas. Programa de Pós-graduação em Psicologia. Rua Aristides Novis, 197, Federação, Salvador-BA, Brazil. CEP 40.210-630. E-mail: emanuelmssilva@gmail.com 
Personal epistemology has been broadly defined as an individual's beliefs about the nature of knowledge and knowing and has become a prominent line of investigation, especially for educational researchers (Greene, Sandoval, \& Bråten, 2016; Holma \& Hyytinen, 2015). According to Fagnant and Crahay (2011), researchers in this field have combined different theoretical approaches to address mainly questions regarding the certainty and simplicity of knowledge (that is, the nature of knowledge) and the source of knowledge and justification of knowing (that is, the nature of knowing). Methodologically, these issues have been usually assessed using self-report questionnaires intended to measure different dimensions of personal epistemology (Fagnant \& Crahay, 2011; Holma \& Hyytinen, 2015; Muis et al., 2015; Greene et al., 2016).

A series of empirical studies have been conducted to examine the relations between personal epistemology and other psychological variables (Holma \& Hyytinen, 2015; Muis et al., 2015). In the educational field, for instance, students' epistemic beliefs have been associated with cognition, motivation, learning, and achievement, thus corroborating the hypothesis that personal epistemology influences different dimensions of students' behavior (for example, text comprehension and problem solving) (Greene et al., 2016; Muis et al., 2015). However, other fields of inquiry within psychology have also been drawn to the study of how personal epistemology is related to their subject matter. One of these fields is psychotherapy.

In the last decades, psychotherapy researchers have been interested in issues associated with personal epistemology in different domains related to clinical practice, such as practitioner education and theoretical orientation choice (Arthur, 2000, 2001; Demir \& Gazioglu, 2012; Heffler \& Sandell, 2009; Schacht \& Black, 1985); therapist self-care (Brucato \& Neimeyer, 2009); working alliance and use of therapeutic techniques (Lee, Neimeyer, \& Rice, 2013); and therapy outcomes (Toska, Neimeyer, Taylor, Kavas, \& Rice, 2010). This growing interest has rested on the premise that psychotherapists' epistemic commitments may influence affective, behavioral, and cognitive aspects related to their practice. As such, researchers have argued that psychotherapists' personal epistemologies should be emphasized in training and professional development (Lee et al., 2013; Toska et al., 2010). In fact, some authors (Greene \& Yu, 2016; Hoshmand, 1994; Thompson, 2014) have claimed that learning about one's epistemic orientation in professional education (for example, psychotherapy training) may help future practitioners develop critical thinking skills, evaluate different sources of knowledge or perspectives, and deal with differences in a constructive manner.

Psychotherapy researchers who are interested in issues associated with therapists' personal epistemology have frequently cited Royce's (1973) theory of knowledge (Arthur, 2001; Lee et al., 2013; Toska et al., 2010), which postulated that knowing involves basic modes (that is, rationalism, empiricism, and metaphorism). These modes of knowing may differ in terms of their justification criteria and dependence on cognitive processes. For example, knowing in the arts is different from knowing in the mathematics. The first field usually tests the validity of knowledge in terms of universality of insights and is largely dependent on symbolization; the second field tests the validity of knowledge by its logical consistency and is largely dependent on conceptualization or rational analysis.

Based on his research on multi-trait individuality, Royce (1973) developed a psycho-epistemology model that emphasizes three basic modes of knowing, namely, rationalism, empiricism, and metaphorism. Rationalism (R) relies mainly on clear thinking, logical consistency, and rational analysis of ideas. Empiricism (E) involves active observation and seeking of sensory experience. Metaphorism (M) focuses on symbolic cognitions and universal insights or awareness. These modes of knowing are basic due to their association with underlying cognitive processes (for example, conceptualizing in rationalism, perceiving in empiricism, and symbolizing in metaphorism). Furthermore, Royce acknowledged that individuals' different modes of knowing could be combined in an order of preference to obtain a hierarchical structure. Thus, the combination of these dimensions leads to six different hierarchically-based styles or orientations, namely, Empirical-Metaphorical-Rational (EMR), ERM, MER, MRE, REM, and RME. Royce and Mos (1980) claimed that these hierarchies may help account for individual differences in worldview and behavior. They also considered that all three modes of knowing are interrelated legitimate approaches to reality, each of which can lead to either truth or error. Royce (1973) further noted that an individual might be partial to one or other mode of knowing (that is, a dominant mode). This partiality may lead to a phenomenon termed as encapsulation, that is, a strong, and sometimes inflexible, tendency to view the world and act mostly according to one's dominant way of knowing.

To assess the psycho-epistemological commitments of an individual, Royce and Mos (1980) developed a standardized inventory, namely, the Psycho-Epistemological Profile (PEP). The PEP is a 90-item self-report instrument in Likert-scale format (five points: 1 = strongly disagree and $5=$ strongly agree), in which respondents endorse their level of agreement with the items (for example, "My intellect has been developed most by learning methods of observation and experimentation" - Empiricism dimension; "I like to think of myself as logical - Rationalism dimension; When playing bridge or similar games, I play the game following spontaneous cues" - Metaphorism dimension). Each PEP subscale contains 30 items, and the highest scoring dimension will indicate the dominant epistemology for that person. The scale shows good psychometric properties, with high test-retest reliability coefficients, ranging from 0.80 to 0.90 . Factor analyses indicated the existence of three independent scales consisting of empirical, rational, and metaphorical contents. Correlations among the three approaches were 0.63 (Rationalism and Metaphorism), 0.51(Empiricism and Metaphorism), and 0.63 (Rationalism and Metaphorism). 
The Cronbach alphas ranged from 0.67 to 0.80 (Royce \& Mos, 1980).

Rancourt (1990) further developed Royce and Mos's ideas in the educational field through his Epistemic Orientation Model. Similar to Royce and Mos (1980), Rancourt (1990) proposed three basic modes of accessing and using knowledge, namely, rational, empirical, and noetic modes. In Rancourt's view, the noetic mode encompasses mainly the intuitive, gut-feeling qualities of knowledge acquisition and use, whereas Royce and Mos's metaphoric dimension emphasizes aesthetic and symbolization elements. Both models are based on a hierarchy of preferences, in which the ordering of modes or dimensions allows us to identify an individual's epistemic orientation.

In the field of psychotherapy, several scholars have empirically explored the associations between practitioners' dominant epistemic orientation and different elements of the psychotherapeutic process. For instance, Toska et al. (2010) noted that therapists endorsing a rational epistemology were found to be more directive and to put less emphasis on the affective aspects of therapy. By contrast, therapists with constructionist epistemology were described as more flexible and tolerant of ambiguity. In another study, Lee et al. (2013) found that psychotherapists who endorsed a rationalist epistemology were more likely to report planning their interventions and using techniques for changing dysfunctional thoughts in their practice. By comparing epistemological commitments between psychoanalysts and behavior therapists, Schacht and Black (1985) found that psychoanalysts showed a stronger leaning toward metaphorism, whereas behavior therapists had higher mean rationalism scores. In a study conducted by Arthur (2000), psychoanalysts were more likely to describe themselves as intuitive and metaphorical, whereas cognitive-behavior therapists tended to view themselves as more rational. The two groups showed no difference in terms of empiricism. Taken together, these findings reveal the potential influence of personal epistemology on therapy variables (for example, therapist behavior, theoretical orientation choice, and use of techniques). In this context, recent studies have pointed out the need to develop a line of inquiry in which researchers can investigate the translation of personal epistemology into practice (Lee et al., 2013; Toska et al., 2010). This emerging field of research within psychotherapy may be advanced by the development of short measures of epistemic orientation with good psychometric properties.

Although Royce's model has been used to investigate psychotherapists' epistemological stances before (Arthur, 2001; Schacht \& Black, 1985), several researchers have pointed out the need for shorter and updated measures of epistemic orientation (Arthur, 2001). For instance, completing the PEP may take up to 40 minutes. Furthermore, since it was mainly developed in the 1960s and 1970s and has never been substantially revised, the PEP contains many items with outmoded language; some of which may not accurately reflect the proposed dimensions according to some authors (Arthur, 2000; Wilkinson \& Migotsky, 1994).
Other points regarding the investigation of personal epistemology in the field of psychotherapy research include the small number of participants for some therapist subgroups based on theoretical orientation, the employment of small and sometimes non-representative samples, and the use of measures with poor psychometric properties (Arthur, 2001). These studies have also been characterized by emphasis on only two theoretical orientation groups (psychoanalysis vs. cognitive or cognitive-behavior therapy). In the present study, we tried to address some of these issues by using sufficient subgroup sizes (at least, 50 participants per theoretical orientation group) and approaches that are most likely to be endorsed by the majority of practitioners in the field (for example, cognitive therapy, behavior analysis, psychoanalysis, and humanistic-existential). Participants were selected mainly from recognized orientationcommitted professional bodies and societies (for example, National Association of Psychoanalysts and Cognitive Therapy Society). In this context, the main objective of this study was to develop and provide initial validity evidence for brief measure of epistemic orientation in a sample of Brazilian psychotherapists.

\section{Method}

First, the constructs that would guide the initial writing and assembling of items were articulated based on Royce and Mos's (1980) theoretical model and measurement instrument, the PEP, and Rancourt's (1990) Epistemic Orientation Model. Partially consistent with the models proposed by these authors, epistemic orientation was defined as an individual's preferred way of accessing and using knowledge consisting of three modes or dimensions, namely, Rationalism, Empiricism, and Intuitionism. In contrast to Royce and Mos's metaphorism dimension but consistent with Rancourt's noetic mode, in the present study, the intuitionism dimension emphasized "gut-feelings," affective aspects of epistemic experience. The dimensions were initially defined as follows. Rationalism emphasizes the acquisition and use of knowledge through concepts, theories, and logical analysis, thus favoring deductive reasoning. Empiricism entails the use of perceptual, sensory experience, observational processes, and experimentation for knowledge acquisition and use, thus favoring inductive reasoning. Intuitionism focuses mainly on affective experiences (for example, feelings and gut feelings) as a source of knowledge acquisition and use, thus favoring subjective processes.

Once the constructs were articulated, an initial pool of items was assembled. Some new items were written specifically for this instrument, whereas other items were directly borrowed from the PEP with slight modifications (for example, "I like to think of myself as logical"). As we intended to have a short measure, we initially proposed 49 items (about 16 per dimension) because the number of items usually tends to decrease during scale development and validation. Notably, items that were borrowed from the PEP 
were translated and then back-translated by two independent professionals who were proficient in both languages (English and Portuguese). The original and translated items were compared to evaluate coherence, content agreement, language use, and clarity. Moreover, different situations (for example, knowledge acquisition in new situations, decisionmaking, and self-perception) were considered to cover varied modes of manifestation of an individual's epistemic orientation. Finally, a six-point Likert type scale was chosen, in which respondents could indicate the degree to which each item described them $(1=$ doesn't describe me at all, $6=$ describes me very well).

An initial questionnaire containing the definitions of each dimension and the 49 randomly distributed items was created and sent to eight independent evaluators, all of whom were researchers with a master's or PhD degree in psychology and some experience in scale construction and validation. These researchers were asked to rate the items in terms of the degree to which each item reflected the intended dimensions and to evaluate item clarity. Based on the level of agreement among raters and their evaluation of the items, some items were discarded due to lack of intelligibility or inadequate reflection of the dimensions proposed. Other items were rewritten or revised. Eventually, 15 items (five per dimension) were assembled and comprised the initial version of the questionnaire. In a pilot test, this 15 -item questionnaire was administered to a group of 10 psychotherapists of different theoretical orientations so that they could evaluate its clarity and ease of use. Psychotherapists' feedback was positive, and no more modifications were made. The questionnaire was then considered appropriate for use.

\section{Participants}

Participants were 674 psychotherapists, of which $88.6 \%(n=597)$ were self-identified as psychologists, $7.3 \%(n=49)$ were doctors, and $4.2 \%(n=28)$ were other professionals. The majority of participants were women, $78.5 \%(n=529)$. The mean age was 42.02 years $(S D=$ 13.06, age range 22-78 years). Most participants indicated their primary employment setting as private practice $(92 \%$, $n=620)$, employed in hospitals $(4.5 \%, n=30)$, employed in psychosocial support centers $(3.3 \%, n=20)$. The remaining participants indicated that their primary employment settings were others, including community centers, schools, correctional facilities, and school clinics. The mean number of years spent in clinical practice was $12.84(S D=11.18)$, ranging between 1 and 50 years for 653 psychotherapists. Twenty-one psychotherapists spent less than 1 year in clinical practice. The mean number of weekly hours of practice was $23.49(S D=13.90)$. Participants identified psychoanalysis as their primary theoretical orientation $(25.2 \%, n=170)$, followed by behavior analysis $(19.6 \%, n=132)$, cognitive $(18.2 \%, n=123)$, humanistic-existential $(13.4 \%, n=90)$, analytical $(11.4 \%, n=77)$, systemic $(7.4 \%, n=50)$, and others $(4.8 \%, n=32)$. Other approaches included psychodrama, esquizo-analysis, and integrative psychotherapy.

\section{Instruments}

Epistemic Orientation Short Scale (EPOSS). A 15-item self-report instrument used to assess individual epistemic orientation. EPOSS is a six-point Likert type measure $(1=$ doesn't describe me at all, $6=$ describes me very well) and consists of three dimensions: Rationalism (for example, "I tend to make decisions based on reasons I can clearly explain"); Intuitionism (for example, "In new situations, I acquire knowledge based on the feelings the environment evokes in me"); and Empiricism (for example, "I tend to make decisions based on my observations and practical experiences"). The scale uses a stem sentence format, with each sentence followed by three different endings (for example, "I tend to make decisions based on..."). The highest scoring dimension will provide the individual's most salient epistemic orientation.

Socio-demographic questionnaire. This instrument contains questions related to therapist's age, gender, years spent in practice, predominant theoretical orientation, hours of work per week, and main employment setting.

\section{Procedure}

Data collection. An invitation e-mail containing a link to a webpage where participants could complete the questionnaire was sent to psychotherapists affiliated with orientation-committed bodies, such as societies of psychoanalytic, cognitive, behavioral, systemic, humanistic-existential, and Junguian (that is, analytical) psychotherapists. Therapists were also contacted through their personal websites and specialized sites where they advertised their services. Before accessing the questionnaire, respondents had to read the informed consent and agree to participate by checking the appropriate box. A total of 1.233 individuals visited the website, of which 674 completed the whole questionnaire (54.9\% completion rate).

Data analysis. The sample was randomly divided into three subsets (Sample 1, $n=231$; Sample 2, $n=221$, and Sample 3, $n=222$ ) to conduct a series of exploratory and confirmatory factor analyses and cross-validation of the model. Subsample one was used to carry out the exploratory factor analysis (principal factor analysis with oblique rotation Direct Oblimin). A confirmatory factor analysis was conducted on the second subsample using AMOS (v. 22, SPSS, IBM). Normality was assessed by checking problematic levels of skewness $(>3)$ or kurtosis $(>10)$, and Mahalanobis Distance $\left(D^{2}\right)$ was used to identify multivariate outliers. According to the recommendations of some authors (Brown, 2015; Marôco, 2014), the following fit indices were used in the analysis: chisquare $\left(X^{2}\right) / d f(\sim 2-3)$, comparative fit index (CFI $\left.>0.90\right)$, goodness of fit index (GFI $>0.90)$, root mean square error (RMSEA < 0.08), and Bayes information criterion (BIC) for comparing models. Internal consistency was assessed using Cronbach alpha and composite reliability. According to the recommendations of Marôco (2014), 
average variance extracted (AVE) was calculated to assess convergent validity (AVE $>0.50$ ); discriminant validity was assessed by comparing the squared correlations between two factors, with the AVE of each factor, and associations smaller than the individual AVE indicate discriminant validity. The third sample was used to crossvalidate the model. Lastly, the criterion validity of the measure was evaluated. Multivariate analysis of covariance (MANCOVA), controlling for gender (dummy coded), years spent in practice, and hours of work per week, was conducted on the overall sample to examine differences in the adjusted mean scores of epistemic orientation as a function of therapists' theoretical orientation.

\section{Ethical Considerations}

The Institutional Review Board at Faculdade Adventista da Bahia approved the project of which this study was a part (CAAE: 37816214.7.0000.0042).

\section{Results}

The presentation of results is divided into three sections: (1) exploratory factor analysis; (2) confirmatory factor analysis and cross-validation of the model, and (3) determination of the relations between epistemic orientation and psychotherapists' theoretical approaches.

\section{Exploratory factor analysis}

The Kaiser-Meyer-Olkin (KMO) measure verified the sampling adequacy for analysis $(\mathrm{KMO}=0.80)$, and all $\mathrm{KMO}$ values for individual items were greater than 0.70 , which is above the acceptable limit of 0.50 (Field, 2013). An initial analysis was run to obtain eigenvalues for each factor in the data. Three factors had eigenvalues over the Kaiser's criterion of 1 and, in combination, accounted for $50.18 \%$ of the variance. The scree plot suggested the possibility of retaining three factors. Analysis of the pattern matrix revealed that two empiricism items, namely, "I see myself as someone who is practical and realistic" (emp4) and "My opinions are commonly based on concrete facts and observations" (emp5), were loaded on the rationalism dimension. Both items were initially discarded from the analysis because they were directly borrowed from the PEP and underwent slight modifications. Another principal factor analysis with a fixed number of three factors to extract was conducted on the 13 remaining items by using the same rotation technique. The KMO value was 0.75 , and all $\mathrm{KMO}$ values for individual items were greater than 0.70 . The three factors explained $45.98 \%$ of the variance. Analysis of the pattern matrix revealed that all items were loaded on the intended dimensions, with factor loadings ranging from 0.33 to 0.90 . The correlations between the dimensions were -0.15 (Rationalism and Intuitionism), 0.22 (Intuitionism and Empiricism), and 0.33 (Rationalism and Empiricism). The Cronbach alphas were $\alpha=0.71$ (Rationalism), 0.72 (Empiricism), and 0.77 (Intuitionism). Table 1 shows the factor loadings for the Oblimin threefactor solution for the items of the Epistemic Orientation Short Scale (EPOSS).

Table 1

Factor Loadings for the Oblimin Three-Factor Solution for the Items of the Epistemic Orientation Short Scale

\begin{tabular}{lc}
\hline Item & $\begin{array}{l}\text { Factor } \\
\text { loading }\end{array}$ \\
\hline Factor I: Intuitionism & \\
\hline $\begin{array}{l}\text { Int } 5 \text { - My opinions are commonly based on feelings } \\
\text { and intuitions (15) }\end{array}$ & 0.90 \\
$\begin{array}{l}\text { Int } 4 \text { - I see myself as someone who is intuitive and } \\
\text { spontaneous (10) }\end{array}$ & 0.72 \\
$\begin{array}{l}\text { Int } 3 \text { - I tend to make decisions based on what feels } \\
\text { right (true) to me (7) }\end{array}$ & 0.60 \\
$\begin{array}{l}\text { Int } 2 \text { - In new situations, I acquire knowledge based on } \\
\text { the feelings the environment evokes in me (4) }\end{array}$ & 0.57 \\
$\begin{array}{l}\text { Int } 1 \text { - I deal best with contexts involving mainly } \\
\text { spontaneity and sensitivity (3) }\end{array}$ & 0.42 \\
\hline $\begin{array}{l}\text { Factor II: Rationalism } \\
\text { Rac } 5 \text { - My opinions are commonly based on logical } \\
\text { and rational principles (13) }\end{array}$ & 0.86 \\
$\begin{array}{l}\text { Rac } 4 \text { - I see myself as someone who is logical and } \\
\text { analytical (11) }\end{array}$ & 0.70 \\
$\begin{array}{l}\text { Rac } 3 \text { - I tend to make decisions based on reasons I } \\
\text { can clearly explain (8) }\end{array}$ & 0.68 \\
$\begin{array}{l}\text { Rac } 1 \text { - I deal best with contexts involving mainly } \\
\text { conceptual and theoretical concerns (1) }\end{array}$ & 0.33 \\
$\begin{array}{l}\text { Rac } 2 \text { - In new situations, I acquire knowledge by } \\
\text { reflecting on reality and elaborating on concepts (5) }\end{array}$ & 0.33 \\
\hline \begin{tabular}{l} 
Factor III: Empiricism \\
\hline Emp I I
\end{tabular} & \\
\hline
\end{tabular}

Emp 1 - I deal best with contexts involving mainly concerns with practical experiences and 0.81 observations (2)

Emp 2 - In new situations, I acquire knowledge based on observation and practical experiences (6)

Emp 3 - I tend to make decisions based on my experiences and practical situations (9)

Note. Numbers in parentheses represent the order in which the items appeared in the questionnaire.

\section{Confirmatory Factor Analysis}

No problematic levels of skewness and kurtosis were found. However, the Mahalanobis Distance $\left(\mathrm{D}^{2}\right)$ revealed six multivariate outliers in the second dataset; all of these outliers were removed. In this stage, three models were tested. First, a one-factor model with 15 items was tested and did not fit well $\left(X^{2}=6.48\right.$ and $p<0.0005$, GFI $=0.67$, $\mathrm{CFI}=0.49$, $\mathrm{RMSEA}=0.16$, and $\mathrm{BIC}=744.54)$, suggesting that the epistemic orientation is not a unidimensional 
construct. The initial three-factor model with 15 items was then tested and did not fit well either $\left(X^{2}=3.24\right.$, GFI $=$ $0.84, \mathrm{CFI}=0.83$, RMSEA $=0.10$, and $\mathrm{BIC}=458.88)$. All fit indices for this model were considered poor, indicating that the model needed to be re-specified. The examination of modification indices (MI) revealed that items emp 4 and emp 5 should be associated with other latent variable (that is, Rationalism). Previous exploratory analysis indicated that these items should be temporarily dropped and revised for future research. Even with the removal of these two items, the model did not fit well. A close examination of factor loadings revealed that items "In new situations, I acquire knowledge by reflecting on reality and elaborating on concepts" ( $\operatorname{rac} 2)$ and "I deal best with contexts involving mainly spontaneity and sensitivity" (int1) loaded weakly $(<0.3)$ on the expected dimensions, thereby influencing the model fit. Thus, both items were discarded. With these modifications, the fit of Model III was noticeably better than those of previous models $\left(X^{2}=\right.$ 1.92 , CFI $=0.95$, GFI $=0.94$, and RMSEA $=0.06$ ). The final version of the scale retained the original three-factor structure suggested by the theoretical model proposed by Royce and Mos (1980) and initially intended for this study but discarded items emp 4 and emp5, rac2, and int1. Figure 1 shows the modified model with loadings and correlations among latent variables.

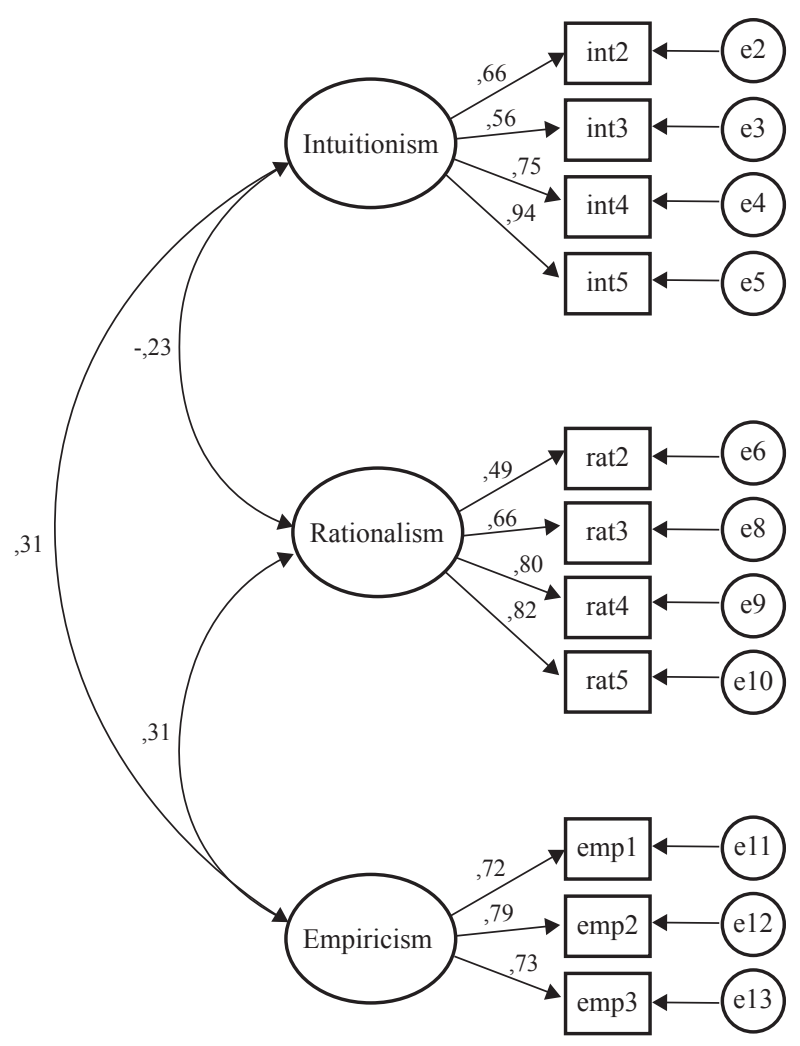

Figure 1. Factor structure and factor loadings of the items in confirmatory factor analysis.
As shown in Figure 1, the loadings for the four variables on the Intuitionism dimension ranged from 0.56 to 0.94 . Meanwhile, the loadings for the four variables on Rationalism ranged from 0.49 to 0.82 , and the loadings for the three variables on Empiricism ranged from 0.72 to 0.79 . The correlation between Intuitionism and Rationalism was 0.23 , and the correlations between Intuitionism and Empiricism and between Empiricism and Rationalism were both 0.31 . These correlations suggested that the latent variables are somewhat associated, as predicted by previous theoretical and empirical research, because they are hypothesized to be dimensions of epistemic orientation. However, these correlations are not so high as to indicate that they are all measuring the same dimensions of the construct.

A composite reliability analysis was conducted to measure the internal consistency of the dimensions by using the method recommended by Marôco (2014) in the context of confirmatory factor analysis. The composite reliability values for each factor were 0.82 (Intuitionism), 0.79 (Rationalism), and 0.79 (Empiricism). All these values are considered very good since they are greater than 0.70 (Marôco, 2014). As an indicator of convergent validity, the average extracted variance (AVE) was calculated; the results revealed acceptable values $(\geq 0.50)$ for each factor: Intuitionism (0.55), Rationalism (0.50), and Empiricism (0.56). Furthermore, discriminant validity was assessed by comparing the AVE of each factor to the squared correlation $\left(r^{2}\right)$ between two factors. The AVE values for Intuitionism (0.55) and AVE for Rationalism (0.50) were greater than $r_{\text {int-rat }}^{2}=0.04$; thus, both factors possess discriminant validity. Likewise, $r_{\text {int-emp }}^{2}=0.09$ and $r_{\text {emp-rat }}^{2}=0.09$ were considerably less than the AVE values for the other factors; as such, discriminant validity was found between Intuitionism and Empiricism and between Empiricism and Rationalism.

\section{Cross-validation of the model}

A new confirmatory factor analysis was carried out on the third subsample $(n=222)$ to test model fit because some data-driven modifications were applied to the model during the confirmatory factor analysis stage. The model fitted reasonably well to the data, with $\mathrm{X}^{2}=2.26$, CFI $=0.94$, $\mathrm{GFI}=0.92$, $\mathrm{RMSEA}=0.08$, and $\mathrm{BIC}=223,451$. Although the indices are slightly different from those in Model III, they may still be considered acceptable (Brown, 2015; Marôco, 2014).

\section{Relations between epistemic orientation and psychother- apists' theoretical approaches}

The criterion validity of the scale was assessed. MANCOVA was conducted to detect intergroup mean differences in the EPOSS dimensions as a function of the theoretical orientation of psychotherapists. Table 2 shows the adjusted means and standard errors of each orientation on the three dimensions that comprise the EPOSS. 
Table 2

Adjusted Means and Standard Errors of Each Theoretical Orientation Group on the Three Epistemic Dimensions

\begin{tabular}{|c|c|c|c|c|}
\hline \multirow[b]{2}{*}{ Orientation } & \multirow[b]{2}{*}{$n$} & \multicolumn{3}{|c|}{ Dimensions } \\
\hline & & $\begin{array}{c}\text { Intuitionism } \\
M(S E)\end{array}$ & $\begin{array}{c}\text { Rationalism } \\
M(S E)\end{array}$ & $\begin{array}{c}\text { Empiricism } \\
M(S E)\end{array}$ \\
\hline Analytical & 77 & $4.70(0.12)$ & $3.67(0.11)$ & $4.76(0.10)$ \\
\hline Behavioral & 132 & $3.66(0.09) *$ & $4.59(0.09) *$ & $5.06(0.07)$ \\
\hline Cognitive & 123 & $3.79(0.09) *$ & $4.59(0.09) *$ & $4.96(0.08)$ \\
\hline Humanistic-existential & 90 & $4.64(0.11)$ & $3.67(0.11)$ & $4.76(0.09)$ \\
\hline Psychoanalytic & 170 & $4.52(0.08)$ & $3.95(0.08)$ & $4.92(0.07)$ \\
\hline Systemic & 50 & $4.38(0.14)$ & $3.66(0.14)$ & $4.81(0.12)$ \\
\hline
\end{tabular}

Note. *significantly different from the other groups, but not from each other. All ps $<0.001$.

The results of the univariate ANCOVA revealed statistically significant intergroup differences for Intuitionism $[F(7,661)=14.26, p<0.001]$ and Rationalism $[F(7,661)=16.47, p<0.001]$ dimensions. By contrast, no statistically significant intergroup differences were found in the Empiricism dimension. Post hoc tests with Bonferroni adjustment were conducted to specify the nature of the intergroup mean differences. The results revealed the emergence of two subgroups: the first subgroup consists of cognitive therapists and behavior analysts, who scored significantly higher on Rationalism; and the second subgroup consists of therapists espousing a psychoanalytical, analytical, humanistic-existential or systemic approach, who scored significantly higher on Intuitionism.

\section{Discussion}

This study investigated the measurement of psychotherapists' epistemic orientation through the construction and validation of a brief measure. This instrument was developed based on previous theoretical and empirical works conducted mainly by Royce and Mos (1980) and models modified by Rancourt (1990). Exploratory factor analysis revealed that most items, except emp 4 and emp 5 , loaded on the intended theory-driven dimensions.

A confirmatory factor analysis was conducted to test different models and achieve a better fitting structure. The best fitting model contained four items on both Intuitionism and Rationalism dimensions and three items on the Empiricism dimension. The 11-item scale was tested on another sample for cross-validation to achieve acceptable fit indices because of some data-driven modifications during the confirmatory analysis stage. Taken together, the findings reveal good initial validity evidence of the three-factor model of epistemic orientation.

A final comparative analysis was carried out to corroborate the validity evidence (for example, criterion validity) of the scale by identifying different levels of rationalism and intuitionism among therapy groups. Psychoanalysts and analytical, systemic and humanistic-existential therapists were more likely to report relying on feelings or intuitions as a source of knowledge acquisition and use. They also tended to view themselves as more intuitive and spontaneous and to make decisions based on what feels right or true to them. Meanwhile, cognitive therapists and behavior analysts were more likely to report relying on deductive reasoning and principles to acquire knowledge and to make decisions based on logic and rational principles. Moreover, they tended to view themselves as logical and analytical people. These findings are consistent with other works. For instance, in a comparative study of the predominant epistemic orientations of psychoanalysts and behavior therapists by using the PEP, Schacht and Black (1985) found that psychoanalysts reported significantly higher levels of metaphorism (that is, a dimension of the PEP that also emphasized intuition) than behavior analysts. Consistent with these findings, Arthur (2000) reported that psychoanalysts were more likely to endorse a metaphorical and intuitive orientation than cognitive-behavior therapists, but no group differences were found regarding empiricism. However, cognitive-behavior therapists reported higher levels of rationalism.

Some of the differences in epistemic orientation may be partly attributed to therapist's training. Some therapists may be initially drawn to a specific theoretical orientation due to their epistemic leanings (for example, rational individuals may be prone to choose a cognitive-behavioral approach), and their predominant epistemic orientations may be reinforced by the academic communities in which they participate; as such, their levels of endorsement of the epistemic commitments of their theoretical orientations increase during the training years. In fact, some authors have suggested that epistemic orientations of individuals become more domain-specific as a result of enculturation into one's specialized area because they progress through high levels of education and professionalization (Hoshmand, 1994; Thompson, 2014). For instance, Heffler and Sandell (2009) found that psychoanalytic-oriented therapists (that is, psychology students) in training were more likely to stick to a "feel and watch" (that is, intuitive and empirical) stance than cognitive and behavior therapists. The latter group was more likely to follow a "think and watch" (that 
is, rational and empirical) approach to work. Importantly, both groups emphasized an observational (that is, watching) approach to therapy.

No consistent comparative data were found in the epistemic orientation of other therapy groups (for example, analytical, systemic, and humanistic-existential). This finding is not surprising because most studies on therapists' epistemic orientation have included few groups, mostly psychoanalysts, cognitive therapists, and behavior therapists (Arthur, 2000; Schacht \& Black, 1985). However, even though some groups may differ from each other in terms of their theoretical grounds, they may be very similar in terms of their approaches to knowing (for example, an intuitive stance). Furthermore, in the present study, the therapy groups did not differ in their levels of empiricism. Arthur (2000) when comparing psychoanalysts and cognitive-behavior therapists reported a similar finding. Therapists, regardless of their theoretical orientations, may equally emphasize acquiring knowledge by using observation and sensory data. In fact, observation may be viewed as a central skill to clinical practice, allowing therapists to monitor different aspects of the therapy process (for example, patients' behavior, posture, tone of voice, speech, thought, and practitioners' own emotional reactions to the patient), especially in initial stages when no clear theoretical analysis has been formulated to guide clinical work.

This study presents some limitations that should be taken into consideration. First, the sample of this study consisted only of psychotherapists with different theoretical orientations, most of whom were self-identified as psychologists. Currently, many professionals from different backgrounds (for example, medicine and social work) practice psychotherapy, and the differences in their background may partially influence one's epistemic orientation. Therefore, the results of this study concerning the differences among different theoretical orientations based on epistemic orientation should be taken cautiously. Furthermore, future research should test the developed model of epistemic orientation on other professional groups, especially those that, similar to the psychotherapy field, have a vast array of specializations within its area.

In terms of scale construction and validity evidence, future research should investigate the relationship between the model of epistemic orientation and other psychological variables (for example, career choice, emotion regulation, and motivation). Recent studies have revived an interest in personal epistemology as it may guide human behavior in different domains (Brucato \& Neimeyer, 2009; Elphinstone \& Critchley, 2016; Lee et al., 2013; Tamir, 2015). Thus, future investigations in this field may provide strong evidence of the concurrent, discriminant, and predictive validity of the scale. In spite of its limitations, the present study contributed to the advancement of knowledge in the growing field of personal epistemology by providing initial validity evidence of a short measure of epistemic orientation. In terms of psychotherapy research, specifically, this study contributed to the understanding of the epistemic commitments of therapists of different theoretical orientations. Additionally, the process of scale construction and validation used a large sample, allowing the use of a robust split-sample design and different factor analytical techniques to obtain a short scale with good psychometric properties. This measure can also be used for training purposes to make psychotherapy students aware of their epistemic commitments and how these factors might affect their practice. Some authors (Arthur, 2000; Lee et al., 2013) suggest that therapists' epistemic assumptions may affect their case conceptualization and guide their interventions, bearing some important implications for the psychotherapeutic process. In fact, becoming aware of one's personal epistemology may be an important step in developing sophisticated and flexible forms of thinking, which is a relevant competency for clinical practice.

\section{References}

Arthur,A. R. (2000). The personality and cognitive-epistemological traits of cognitive-behavioural and psychoanalytic psychotherapists. British Journal of Medical Psychology, 73(Pt 2), 243-257.doi:10.1348/000711200160453

Arthur, A. R. (2001). Personality, epistemology, and psychotherapists' choice of theoretical model: A review and analysis. European Journal of Psychotherapy, Counselling and Health, 4(1), 45-64. doi:10.1080/13642530110040082

Brucato, B., \& Neimeyer, G. (2009). Epistemology as a predictor of psychotherapists' self-care and coping. Journal of Constructivist Psychology, 22(4), 269-282. doi:10.1080/10720530903113805

Brown, T. A. (2015). Confirmatory factor analysis for applied research (2nd ed.). New York, NY: Guilford.

Demir, I., \& Gazioglu, E. I. (2012). Theoretical orientations of Turkish counselor trainees: The role of thinking styles, epistemology and curiosity. Psychology, 3(7), 527-533. doi:10.4236/psych.2012.37077

Elphinstone, B., \& Critchley, C. (2016). Does the way you think and look at the world contribute to being materialistic? Epistemic style, metaphysics, and their influence on materialism and wellbeing. Personality and Individual Differences, 97, 67-75. doi:10.1016/j.paid.2016.03.004

Fagnant, A., \& Crahay, M. (2011). Theories of mind and personal epistemology: Their interrelation and connection with the concept of metacognition. European Journal of Psychology of Education, 26(2), 257-271. doi:10.1007/ s10212-010-0045-2

Field, A. P. (2013). Discovering statistics using SPSS (5thed.). Thousand Oaks, CA: Sage.

Greene, J. A., Sandoval, W. A., \& Bråten, I. (2016). Handbook of epistemic cognition. New York, NY: Routledge. 
Greene, J. A., \& Yu, S. B. (2016). Educating critical thinkers: The role of epistemic cognition. Policy Insights from the Behavioral and Brain Sciences, 3(1), 45-53. doi:10.1177/2372732215622223

Hoshmand, L. L. T. (1994). Orientation to inquiry in a reflective professional psychology. New York, NY: State University of New York Press.

Heffler, B., \& Sandell, R. (2009). The role of learning style in choosing one's therapeutic orientation. Psychotherapy Research, 19(3), 283-292. doi:10.1080/1050330090280673

Holma, K., \& Hyytinen, H. (2015). The philosophy of personal epistemology. Theory and Research in Education, 13(3), 334-350. doi:10.1177/1477878515606608

Lee, J. A., Neimeyer, G. J., \& Rice, K. G. (2013). The relationship between therapist epistemology, therapy style, working alliance, and interventions use. American Journal of Psychotherapy,67(4),323-345.

Marôco, J. (2014). Análise de equações estruturais: Fundamentos teóricos, software \& aplicações [Analysis of structural equations: Theoretical foundations, software \& applications]. Pêro Pinheiro, Portugal: Report Number.

Muis, K. R., Pekrun, R., Sinatra, G. M., Azevedo, R., Trevors, G., Meier, E., \& Heddy, B.C. (2015). The curious case of climate change: Testing a theoretical model of epistemic beliefs, epistemic emotions and complex learning. Learning and Instruction, 39, 168-183. doi:10.1016/j. learninstruc.2015.06.003

Rancourt, R. (1990). Le guide du consultant pour l'interprétation des styles épistémiques [Epistemic style interpretation guide for consultants]. Ottawa, Canada: Les Éditions Impact.

Royce, J. R. (1973). Epistemic styles, individuality, and world-view. ETS Research Bulletin Series, 2, 1-50. doi:10.1002/j.2333-8504. 1973.tb00854.x

Royce, J. R., \& Mos, L. P. (1980). Manual, Psychoepistemological profile. Edmonton, Canada: The University of Alberta.

Schacht, T. E., \& Black, D. A. (1985). Epistemological commitments of behavioral and psychoanalytic therapists. Professional Psychology: Research and Practice, 16(2), 316-323.doi:10.1037/0735-7028.16.2.316

Tamir, M. (2015). Why do people regulate their emotions? A taxonomy of motives in emotion regulation. Personality and Social Psychology Review, 20(3), 199-222. doi:10.1177/1088868315586325

Thompson, R. J., Jr. (2014). Beyond reason and tolerance: The purpose and practice of higher education. New York, NY: Oxford University Press.
Toska, G. A., Neimeyer, G.J., Taylor, J.M., Kavas, A.B., \& Rice, K.G. (2010). Epistemology and allegiance: Exploring the role of therapists' epistemic commitments on psychotherapy outcomes. European Journal of Psychotherapy and Counselling, 12(1), 65-77. doi:10.1080/13642531003637783

Wilkinson, W. K., \& Migotsky, C. P. (1994). A factor analytic study of epistemological style inventories. Journal of Psychology, 128(5), 499-516.doi:10.1080/00223980.19 94.9914909

Emanuel Missias Silva Palma holds a doctoral degree in psychology from the Universidade Federal da Bahia.

Sônia Maria Guedes Gondim is a Professor at the Universidade Federal da Bahia.

Carolina Villa Nova Aguiar is a Professor at the Escola Bahiana de Medicina e Saúde Pública.

Received: Jun. 8, 2016

1st Revision: Nov. 17, 2016

Approved: Feb. 2, 2017

How to cite this article:

Palma, E. M. S., Gondim, S. M. G., \& Aguiar, C. V. N. (2018). Epistemic Orientation Short Scale: Development and Validity Evidence in a Sample of Psychotherapists. Paidéia (Ribeirão Preto), 28, e2817. doi:http://dx.doi.org/10.1590/1982-4327e2817 